Marquette University

e-Publications@Marquette

$1-1-2009$

\title{
Competing Conceptions of the Individual in Recent Economics
}

John B. Davis

Marquette University, john.davis@marquette.edu

Published version. "Competing Conceptions of the Individual in Recent Economics," in The Oxford Handbook of the Philosophy of Economic Science. Eds. Don Ross and Harold Kincaid. Oxford, NY: Oxford University Press, 2009: 223-244. DOI. (C) 2009 Oxford University Press. Used with permission. 


\section{Introduction}

In the last two decades, the economics research frontier has been significantly transformed by the emergence of a collection of new approaches that criticize traditional neoclassical assumptions, and whose origins lie largely in other sciences. ${ }^{-}$If changes in the research frontier herald future changes in economics (Davis 2006b), that the new methods and concepts being adopted in economics come from other sciences strongly suggests that economics will be substantially different in the future. This invites us to inventory the traditional neoclassical assumptions that have been the target of these recent critiques, and ask what alternative assumptions are being proposed as their replacements. Here I focus on one of the most fundamental commitments of neoclassicism under question, the conception of the individual human being as an economic agent. The traditional assumption under challenge is that of the human individual as an atomistic being, Homo economicus. But rather than there being one single alternative conception of the individual on the agenda in the new work on the research frontier, there are a variety of different conceptions and elements of conceptions of individuals under investigation as befits the different origins of the new ideas in economics in different sciences. The task before us, then, is to distinguish these different conceptions and evaluate their prospects within economics.

Why is the conception of the individual in economics a matter of central importance? First, since the conception of what an individual is underlies the conception of an economic agent, failure to adequately articulate the former leads to ambiguity regarding what agents are as well as regarding how cause-and-effect processes operate in economic life. Second, the conception of the individual economic agent constitutes an ontological anchor for economic analysis, such that failure to develop an adequate conception of the individual jeopardizes the realism of economic analysis. Third, on the assumption that economics is about human individuals, having an adequate conception of the individual is important for the human relevance of economics.

One way to begin is to identify the principal weaknesses of the Homo economicus conception. Despite its long-standing appeal, systematic examination of the conception, as I have pursued using personal identity analysis (Davis 2003b), shows that the conception neither allows us to individuate human beings in the sense of showing them to be distinct agents, nor allows us to reidentify them across change in the sense of showing them to be enduring agents. The first criterion is synchronic, or oriented toward phenomena considered within limited time frames, and the second is diachronic, or oriented toward phenomena considered over periods of time. Note, then, the following three points: First, that the neoclassical Homo economicus conception satisfies neither criterion means that any alternative conception of the individual can at least improve upon it by satisfying one of the two criteria without yet being entirely satisfactory in addressing them both. Second, that the conception of the individual is generally not the primary focus in the new research programs in economics means that there is often limited sensitivity to the need to address both synchronic and diachronic dimensions. Third (and most importantly for what follows), that the new research programs can generally be differentiated according to whether they emphasize synchronic or diachronic concerns means that they are more disposed to and more likely successful in making better cases for conceptions of the individual satisfying the criterion that coheres best with their general orientation. 
These points suggest that we should not expect full-blown, comprehensive conceptions of the individual to be associated with the new research approaches in economics, but should rather expect to find a set of arguably incomplete conceptions arranged along a spectrum of synchronic or diachronic concerns. At the same time, it seems only realistic to suppose that any reconciliation or integration of potentially quite different strategies for conceptualizing individuals in the new programs on the research frontier will depend on many other fundamental concerns regarding the redirection of economics other than how one understands the nature of individuality. Here, then, my object is to explore the different research programs' possible "resistances and accommodations" to one another on the subject of how one conceptualizes individuals (Pickering 1995) in the context of their respective strategies for bringing about change in the nature of economics. These "resistances and accommodations," moreover, need to be seen from the perspective of the outside-inside dynamic of change on the research frontier that is driving a process of change in economics generated by science concerns arising outside economics.

I take the leading postneoclassical research approaches to be classical game theory, evolutionary game theory, behavioral game theory, evolutionary economics, behavioral economics, experimental economics, neuroeconomics, and agent-based computational or complexity economics. They can be shown to collectively share the idea that human individuals are not isolated, atomistic beings, but they also differ significantly in how they understand this critique, according, I will argue, to whether they emphasize synchronic or diachronic frames of explanation. Indeed, I will argue that those that adopt the former frame lend themselves more to a microeconomic sort of view, whereas those that adopt the latter frame lend themselves more to a macroeconomic sort of view. Thus, what mutual accommodation and integration might transpire between these different approaches is very much a matter of how these broadly different frames of thinking are re-organized in economics as a result of the importation of new science contents from outside economics.

The idea that human individuals are not isolated, atomistic beings can be explained by saying they are socially embedded (Davis 2003b). This concept has many interpretations, but a basic Cartesian understanding provides an initial intuition. Descartes is famous for his cogito, ergo sum proposition. The equivalent proposition for the embedded individual conception is cogitamus, ergo sum. That is, when individuals act in social contexts, for example, by expressing themselves in first person plural terms, and thereby (normally) bind themselves to the content of their shared assertion, they individuate themselves relative to those to whom the assertion applies. Generally, that is, individuality arises out of relations to others rather than isolation from others. Thus, at issue in the new approaches in economics is how individuality arises out of social interaction, or how individual behavior depends upon aggregate behavior.

To organize the discussion that follows in the next three sections, I characterize the Homo economicus conception in terms of three linked properties that are central to it as an atomist conception. On the standard view, individuals: (1) have exogenous preferences, (2) interact only (or almost only) in an indirect manner with one another through the price mechanism, and (3) are unaffected in these two respects by the aggregate effects of their interaction with one another. As we will see, the new research programs differ in how objectionable they find each of these properties, as befits their different commitments to synchronic or diachronic forms of 
explanation. Thus, another way to see the issue of mutual accommodation and possible adjustment of these new programs to one another with respect to their respective conceptualization of the individual is in terms of the relative significance these three properties have in the different programs according to their respective emphases on synchronic and diachronic concerns.

The discussion that follows these three sections then reviews the role of synchronic and diachronic types of explanations in the possible emergence of a new general research program, discusses embedded individual microfoundations for that general program, and closes with speculations regarding the role of thinking about individuals in a future synthesis of the new research programs.

\section{Exogeneity Under Attack}

The exogeneity assumption underpins neoclassicism's account of how individuals are distinct agents in terms of the idea of each necessarily having only his or her own preferences. Aside from the problematic and circular character of the idea of one's own preferences, ${ }^{2}$ there are two related ways in which the exogeneity assumption has been challenged in the recent new approaches: (1) nonsubjective factors are shown to influence individual preferences via framing effects, and (2) preferences are seen to reflect the kind of environment the individual or agent occupies. In both cases, preferences cease to be strictly the agent's own preferences, effectively becoming socially embedded rather than atomistic. However, the way in which this occurs differs according to whether the approach is more synchronic (or microeconomic) or more diachronic (or macroeconomic), and this has implications for the kind of embedded individual conception developed. I discuss the first case in connection with the rise of behavioral economics and behavioral game theory and the second case in connection with the rise of one version of computational economics, namely, agent-based computational economics.

\section{Behavioral Economics and Behavioral Game Theory}

There have long been doubts in and out of economics about the realism of the exogeneity assumption, but since Maurice Allais's (1953) discovery of common consequence and common ratio effects at odds with expected utility theory's independence axiom, and subsequent experimental evidence of preference reversals in the choice of lotteries showing how orderings depend on preference elicitation procedures (Lichtenstein \& Slovic 1971), doubts about exogeneity have been focused on the independence axiom. The independence axiom states that, given the choice between two things, an individual's preference for one over the other is unaffected by the introduction or presence of a third thing. Behavioral economics, particularly as it has emerged from the work of Daniel Kahneman and Amos Tversky, has made abandonment of the independence axiom central to a new view of the individual that adds a procedural element to choice behavior in supposing that individuals rely on a variety of decision heuristics or rules sensitive to context to frame their choices. Thus, in Kahneman and Tversky's prospect theory (1979), choice is a two-phase process with prospects "edited" in the first phase using different decision heuristics, such that choices are then made in the second phase from a restricted or reformulated class of prospects. This two-phase analysis makes it possible to look at gains and 
losses relative to reference points, and ultimately introduces well-observed phenomena at odds with standard framework predictions, such as status quo bias and loss aversion (Tversky \& Kahneman 1992). More generally, prospect theory opens the door to the investigation of a variety of descriptive and procedure invariance failures that cast doubt on the traditional idea that individuals possess stable and coherent preferences.

Thus, with this view, preferences are malleable and dependent on the context in which they are elicited (Camerer \& Loewenstein 2003), and choice involves processes whereby individuals effectively construct their preferences (Payne, Bettman \& Johnson 1992; Slovic 1995). Defenders of the traditional exogeneity assumption, in contrast, have argued for a "discovered preference hypothesis," as coined by Charles Plott (1996; also cf. Smith 1989; Harrison 1994; Binmore 1999), which assumes that individuals have coherent and stable preferences, and though those preferences are not necessarily immediately revealed in their decisions, they can be discovered to underlie their apparent preferences, should individuals engage in information gathering, deliberation, and trial-and-error learning. But the case for "discovered preferences" is by no means a simple one, and in any event has not been persuasive to many who favor a more empirically based behavioral approach to economics (Cubitt, Starmer \& Sugden 2001).

One particularly clear application of these conclusions lies in behavioral game theory research. In a widely replicated experiment, laboratory subjects engage in a form of interaction called the ultimatum game, and experimenters test the hypothesis that individuals might act out of a motivation contrary to their self-interest, namely, a sense of reciprocity or a desire to respond in kind to the actions of others, whether for good or bad, depending on the context or institutional framing of their interaction. The self-interest postulate is reflective of the exogeneity assumption, because many neoclassical economists take it to be tautologically true on the belief that individuals necessarily act on their own preferences. Experimental researchers have found, however, that laboratory subjects behave consistently or inconsistently with the self-interest hypothesis according to context and institutional framing (Fehr \& Gächter 2000; cf. Samuelson 2005). This result has been experimentally generalized to a variety of other types of games, such as the public-goods game, and has subsequently given rise to a new area of investigation called social-utility/social-preferences research (Camerer \& Fehr 2004).

The general conclusion of behavioral research on these subjects is that nonsubjective factors influence individuals' preferences via various types of framing effects. But while framing reflects the way the world is presented to an individual, so that the behavioral conception of the individual is an embedded rather than an atomistic one (and presumably, therefore, one of the individual as socially embedded), the behavioral treatment of social is so flat and parsimonious that it includes practically nothing more than the idea that individuals are (or must be) influenced by other individuals. For contrast, and to anticipate what follows, we might note that any conception of individuals that takes them through some sort of developmental or evolutionary process requires a stronger conception of social, because it makes the understanding of the individual depend on changing interaction with others, which expands the idea of social to include social structure. But although some behavioral experiments involve repeated play, the experimental set-up lacks the degree of structural detail in the agent-based approach to computational economics. 


\section{Agent-based Computational Economics and Complexity Accounts}

To understand the nature of social embedding in agent-based approaches to computational economics (agent-based computational economics or ACE), we need to first distinguish an earlier version of computational thinking in economics that has grown out of neoclassical economics, which, in a quite opposite manner, disembeds cognition from individuals. This more traditional form of computational economics derives from postwar artificial intelligence (AI) theory, now known as classical AI. Classical AI, in contrast to later connectionist and neural network AI theory, treats cognition as any (serial) symbol-processing activity understandable in computational terms. Drawing on the computation concept of a Turing machine, $\underline{\underline{3}}$ Noam Chomsky's generative grammar idea, ${ }^{4}$ and the view that the brain itself is merely a computing device,,$\frac{5}{\text { classical }} \mathrm{AI}$ is functionalist in supposing that cognition may be equated with any and all computations made possible by a given set of functional operations. As functional operations are by nature immaterial, they can, accordingly, be realized or instantiated in a variety of different physical forms. This "multiple realizability thesis" implies that cognition need not be exclusively associated with human beings (or any other particular kind of entity), and thus provided a basis for early AI theory, at least in the weak AI version that seeks to locate cognition in nonhuman physical forms, without supposing they replicate human intelligence.

This early view is adopted in postwar formalist neoclassicism, which, although not explicitly termed a computational economics nonetheless was functionalist in character, gave rise to computational general equilibrium theorizing. $\underline{6}$ Thus the optimization algorithms generated in the development of the Arrow-Debreu-McKenzie axiomatic general equilibrium rational choice models (and later rational expectations models), though originally thought to reflect human reasoning, came to be seen as purely functional in nature, leading to their "disembedding" from human individuals, and instantiation in any number of other types of agents. ${ }^{7}$ In this economics version of the multiple-realizability thesis, then, preferences have no special relation to human beings, and accordingly are neither no longer subjective phenomena, nor serviceable for uniquely distinguishing human individuals, since any imaginable agent — human or nonhuman, individual or group, subpersonal agent or whole agent - could be said to have preferences as defined by that agent's objective function.

For a number of reasons, however, doubts developed about classical AI's functionalist commitment. Particularly influential was John Searle's (1980) Chinese room argument, which concluded that symbol manipulation lacked meaning without a concept of understanding, or that syntax does not suffice for semantics. $\stackrel{8}{-}$ Semantics concerns the nature of meaning, and since meaning is always intentional, it presupposes a vantage point from which things take on an "aspectual shape" (Searle 1992, 157). But this meant for Searle that the functionalist disembedding of the mind from the brain is incoherent, because it identified cognition with immaterial operations.

Much of later AI has followed this lead, and assumed that some system of symbol grounding is needed to explain cognition, and that symbol systems are "grounded-up" in nonsymbolic systems (Harnad 1987, 1990). The sort of view this involves - generally termed connectionism, and 
developed in terms of neural networks and parallel distributed processing - is that cognition is not simply symbol manipulation, but rather involves a nonsymbolic/symbolic dynamic process operating on a multilevel basis. The idea that cognition is "grounded-up" has also been expressed as "bottom-up design" and "situatedness" (Brooks 2002). Essentially the idea is that cognition depends on sensory classification systems, which cannot be separated from an entity's place in the world.

In economics, then, though the use of computational methods for solving the Arrow-DebreuMcKenzie axiomatic general equilibrium models continues the early AI functionalist tradition (cf. Amman et al. 1996), an ACE has subsequently also emerged" which explicitly employs a bottom-up type of analysis that models agents in specific environments (cf. Tesfatsion \& Judd, 2006). .9 That is, ACE modeling captures the "ground-up" idea of connectionist AI by adopting a "culture-dish" approach to the study of economies seen as complex adaptive systems. The modeler computationally constructs an economic world comprising multiple interacting agents, where each agent is "an encapsulated piece of software that includes data [about the agent] together with behavioral methods that act on these data," and where agents are both economic agents and represent other social and environmental phenomena (Tesfatsion 2006). After specifying an initial state of the economic system, the economy is allowed to evolve to simulate the dynamics of real-world systems.

Individual behavior, then, is seen to not only reflect the kind of environment the individual or agent occupies, but also to undergo adaptation as changes in that environment feedback to the individual. For example, in Leigh Tesfatsion's simulation model of the labor market, a small number of work suppliers and employers of different types repeatedly interact, each keeps "separate track of his interaction with each potential worksite partner," and continuously updates his or her behavioral rules for different worksites based on what is remembered about past payoffs in past interactions (Tesfatsion 2001,9). The analysis embeds individuals in a social structure, defined in terms of an array of possible labor market interactions, and generates a dynamic account of the behavior of individuals and social structure in which each acts upon the other. This contrasts with the more modest social embedding of individuals in behavioral economics research, where these reciprocal effects are largely absent. The difference may partly be explained in terms of the different methods of investigation - experiment vs. simulationwith the former lending itself more to synchronic analysis and the latter lending itself more to diachronic analysis. But there is also a difference in terms of the way that the social is built-in to the ACE approach. Behavioral economics essentially asks where and how the atomistic conception of the individual breaks down, whereas the ACE approach begins with a situated agent, and never so much as entertains the old atomistic conception.

\section{Interaction Revisited}

The standard view is that individuals interact only (or almost only $\underline{10}$ ) indirectly with one another through the price mechanism. Classical game theory, of course, originates in the rejection of this assumption. Individuals are interdependent in the sense that they know (or have beliefs about) each other's utility functions, know the rules of the games they play with each other, and have common knowledge of this. $\frac{11}{}$ They are thus able to take the actions of others into account in 
making their own decisions, rather than simply responding to price signals. Within this framework there is a wide range of accounts of interdependence and its effects that socially embed individuals in games, though they generally share the restriction that individuals' preferences remain exogenous, and assume that individuals employ traditional expected utility reasoning. Evolutionary game theory, in contrast, puts both exogeneity and standard rationality theory to the test by explaining individual strategies as best responses to selection pressures, such that individuals are effectively only the bearers of strategies that are themselves in competition. Interaction in dynamic game-theoretic contexts thus further embeds individuals, indeed so such so that they arguably lose their status as economic agents. Finally, ACE network theories offer yet a third view of interaction between individuals by supposing that individuals interact both directly and indirectly with other individuals in structures of interaction.

\section{Classical Game Theory}

Here I focus on the contribution of John Harsanyi in light of his explicit elaboration of an alternative conception of the individual as being of a certain type (cf. Davis 2003a). Harsanyi proceeds by adopting two stratagems required to make use of the Nash equilibria framework. First, he argues that games of incomplete information should be treated as a new kind of game of complete information: "the new game $G^{*}$ will be one with complete information because its basic mathematical structure will be defined by the probabilistic model for the game, which will be fully known to both players" (Harsanyi 1995, 295). Second, though he assumes that players employ pure strategies (since this seems more plausible than randomization), they appear to other players to be using mixed strategies if we suppose these apparent mixed strategies are other players' best guesses or conjectures about which pure strategy a player is playing (Harsanyi $1967 / 1968$ ). He then argues that although a complete information game (or C-game) is always analyzed on the assumption that "the centers of activity" are particular individuals, incomplete information games (or I-games) are more clearly formulated as having types of players as their "centers of activity" (Harsanyi 1995, 295).

With this conception, facts about players not known to all players are replaced by probability assessments regarding players' characteristics that are known to all players. Players are represented as types because they may be represented in terms of certain sets of characteristics. Broadly speaking, they may be represented as being certain types, because of "causal factors" or "social forces" in the world that determine what characteristics different individuals are likely to possess (Harsanyi 1995, p. 297)..$\frac{12}{}$ Harsanyi also assumes that players know which type they themselves each represent — "know their own identities" (296) — and rely on this information to assess the probability that other players are of certain types. This makes each player's assessment that another player is of a certain type a conditional probability assessment, one conditional, that is, on knowing one's own type. All players make such assessments and, consequently, any given player (player 1) will act "so as to protect his interests not only against his unknown actual opponent... but ... against all $M$ types of player 2 because, for all he knows, any of them could now be his opponent in the game" (299). Thus, each player's expected payoff depends not just on the strategy of the actual unknown opponent, but also on the strategies of any one of $M$ potential

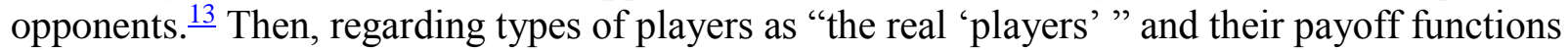
as the "real payoff functions, one can easily define the Nash equilibrium... of this C-game $G^{*}$ " (300). 
Harsanyi's intention to treat individuals as being of certain types involves a significant departure from the standard arm's-length, indirect-interaction view. ${ }^{14}$ His "as if" complete information games not only knits individuals together in the pattern of their choices; it also gives them full accounts of one another, if in a probabilistic sense, in contrast to neoclassicism's assumption of them being inaccessibly subjective about one another. Consequently individuals are socially embedded in the games they play with one another in that their individuality depends on their interaction, in this instance in being recognized as individual types by one another. Despite this, classical game theory retains the standard exogeneity assumption, since interaction never changes individuals' payoff functions. This further step is undertaken in evolutionary game theory.

\section{Evolutionary Game Theory}

Evolutionary game theory (EGT) arose out the application of the theory of games to biological contexts, and the development of the concept of an evolutionarily stable strategy (Maynard Smith \& Price 1973; Maynard Smith 1982). It took on direct economic application in Robert Axelrod's investigation of cooperation (Axelrod 1984), and gained a larger following in economics as a result of disenchantment with the equilibrium refinements project of classical game theory. The central assumption is that players adapt their behaviors in terms of the strategies they play over the course of repeated games. Payoffs represent fitness in some selection process that players achieve by adapting their strategies to the dynamics of competition. Interaction is, thus, both game theoretic and subject to evolutionary forces.

One of the more interesting aspects of EGT is its ambiguity regarding how the players of games are to be understood (cf. Ross, 2005, 194ff). If we see EGT as simply an extension of classical game theory, payers are the human individuals whose choices reflect beliefs about which strategies are the best replies to the strategies of others. But if we suppose that the selection process determines which strategies produce fitness, strategies themselves are the players, and individuals "are simply passive vehicles for these strategies, coming to play their brief hands and then dying off to be replaced by others who inherit their dispositions with modifications induced by mutation and, at the population level, by selection" (Ross 2005, 198; also cf. Sugden 2001). ${ }^{15}$

Thus, if in classical game theory, individuals are socially embedded in the games they play, EGT (arguably so) further embeds them in the dynamics of interaction so as to remove them as agents from the game altogether. That is, EGT effectively turns the standard exogeneity assumption on its head by making particular individuals irrelevant to selection. Here we find an especially clear difference between classical game theory's synchronic perspective and EGT's diachronic perspective.

\section{ACE Network Theories}

Network theory originates in mathematics and graph theory, and today is part of the study of complex systems and nonlinear dynamics. The analysis and study of networks exists in virtually every science (Strogatz 2001), and is an important foundation of ACE. Networks are structures made up of nodes, which can be individuals or groups of individuals, and the links or ties 
between them, which can vary in strength. In the case of economic networks, individuals can thus be said to have both strong ties to some individuals (interact directly) and weak ties to other individuals (interact only indirectly), such as in models of oligopoly firms surrounded by a competitive fringe. Alan Kirman has argued that assuming individuals interact in both ways represents an advance over both general equilibrium theory and game theory, which each assume that individuals interact in only one way - indirectly in the former and directly in the latterassociating this with the Sonnenschein-Mantel-Debreu problems of the former and the equilibrium selection problems of the latter (Kirman 1997; also cf. Rizvi 1994; Davis 2006a). Tesfatsion sees the need to combine direct and indirect interaction in models of markets as an implication of abandoning the artificial Walrasian auctioneer construct in explaining real world interaction between individuals (Tesfatsion 2006).

Distinguishing different kinds of ties and seeing them as interconnected in some way introduces structure into the analysis of individual interaction. Tesfatsion (2001), for example, develops a model of labor markets in which work suppliers and employers interact repeatedly at different kinds of worksites in prisoner's dilemma games. Thus individuals are not only embedded in games with other individuals, but are also embedded in games that are themselves embedded in a social structure. Whereas game theory explains the emergence of social structures in the form of norms and conventions, ACE network theory presupposes such structures in the analysis of games. Indeed, ACE network theory begins with a liberal view of the population of agents, including among them, "individuals (e.g., consumers, workers), social groupings (e.g., families, firms, government agencies), institutions (e.g., markets, regulatory systems), biological entities (e.g., crops livestock, forests), and physical entities (e.g., infrastructure, weather, and geographical regions)" (Tesfatsion 2006,6). This larger cast of agents represents an even further departure from the standard view of interaction than one finds in neoclassicism.

\section{Aggregate Behavior and Feedback}

On the standard view, the relationship of individual behavior to aggregate behavior is unidirectional. Aggregate behavior has individual behavior as its basis, and feedback effects from aggregate behavior to individual behavior are assumed to be absent. Individuals' choice sets are parameterized by aggregate outcomes, but individual preferences remain unaffected and insulated from changes at the aggregate level. One well-known expression of this is the New Classical Macroeconomics microfoundations research program that aims at unifying microeconomics and macroeconomics by aggregating up to macroeconomic relationships strictly in terms of preferences, endowments, and technology. Here I review three challenges to this general view from behavioral game theory, neuroeconomics, and evolutionary economics/ACE complexity thinking. In different ways, all embed individuals in social economic frameworks by allowing for aggregate level feedback effects, which affect individual behavior.

\section{Behavioral Game Theory}

Behavioral game theory departs from classical game theory's rationality focus by applying experimental results from cognitive psychology to the study of individuals' strategic interaction in games (Camerer 2003). By creating complete, self-contained economies in the laboratory 
made up of agents and institutions, researchers are able to generate experimental data that allow them to test a variety of standard theory assumptions. ${ }^{16}$ The kinds of games generally given the most attention are those that exhibit cooperative dilemmas with free rider problems such as the public-goods game (Fehr \& Gächter 2000). The general problem encountered in these games is an equilibrium selection problem in that free-riding equilibria and cooperative equilibria can both exist according to the kinds of institutions (or instructions for experimental subjects) in place. $\frac{17}{}$

In one recent examination of this problem designed to explain the effect of different institutions on individual behavior (Gürerk et al. 2006), an experiment was devised in which players repeatedly choose between two different institutions: one in which individuals chose a level of contribution to a public good, which was then augmented by the experimenter and divided among players, and a second in which the same arrangement applied, but there was also an opportunity for individuals to punish free riders. In initial rounds of the game, free riding prevailed in the no-punishment setup, leading to low payoffs, whereas free riding was punished in the setup in which this was available, leading to higher payoffs. But with repeated play, individuals migrated from the low- to the high-payoff game with the punishment institution.

What the experiment was interpreted to demonstrate was that individuals change their behavior in light of their appraisal of aggregate outcomes. $\underline{18}$ That is, individuals adopt one set of decision rules at the outset, observe their consequences in the aggregate, and then revise their decision rules in light of their observations. This in turn affects the character of overall aggregate behavior by virtue of the increased share of individuals participating in the punishment institution, suggesting that individual and aggregate behavior continuously interact in a cycle of mutual effects on one another. In contrast, in the standard (nonexperimental) framework, such feedback mechanisms do not operate in that rational individuals are always predicted to choose the freeriding institution.

\section{Neuroeconomics}

Neuroeconomics can be seen as an extension of behavioral economics' cognitive science-based revision of standard expected utility reasoning through use of neuroscience imaging techniques to more securely ground observed behavioral propensities in neurological phenomena, and thus as a strategy for making incremental changes in standard theorizing. It may also be seen as offering an alternative framework in the form of an altogether different set of theoretical constructs to explain behavior, and thus as a strategy for making radical departures from standard theorizing (Camerer, Loewenstein, \& Prelec 2005). In the more radical approach, cognitive decision making is thought to employ both deliberative and automatic processes, and cognition and emotion are thought to both contribute to behavior. Taking these two dimensions together gives four possible combinations of neural functioning that can be employed to categorize kinds of human behavior that may operate in parallel, separately (seen as specialization), and in coordination. This implies that individuals are capable of a variety of different possible behaviors, whereas, in contrast, standard theory only allows for behavior explained exclusively in terms of expected utility maximizing.

One way of seeing the neural basis for human behavior, then, is to say that human intelligence is modularized or highly domain (or neuron) specific. This in turn implies that environmental 
triggers can call forth different types of neural activity. For example, in regard to timepreference, whereas standard theory assumes the same degree of time-preference for all intertemporal trade-offs, it can be argued that different contexts elicit different degrees of timepreference according to the deliberative, automatic, cognitive, and affective aspects of the neural processing involved. At the same time, neuroscience research does not support the conclusion that particular types of behavior are always associated with the same brain modules. Brain injury research shows a relatively high degree of plasticity or the ability of the brain to shift functions from one domain to another that has not been impaired. But the shifting of functions can also occur under normal circumstances, such as those associated with learning and experience. Thus reinforcement learning in normal form games has been explained as combining rapid emotional processing - reflecting sense of gain or loss — and a slower deliberative processing - reflecting grasp of counterfactuals (Camerer and Ho 1999).

What emerges from this are views of the brain, behavior, and the environment that involve response and adjustment in a complex array of different possible forms. It would thus be a mistake to say that neuroeconomics research follows the standard model's understanding of the relation of individual behavior to aggregate behavior. ${ }^{19}$ Rather, while aggregate behavior is a product of individual behavior across many individuals, aggregate behavior also exercises feedback effects on individual behavior that it can, in principle, be traced to changes in individual neural functioning. Like behavioral economics and game theory research, much of neuroeconomics research employs laboratory experiments in which experimental subjects play repeated games during brain imaging. Repeated games allow researchers to track changes in behavior associated with experimental subjects' experience across games. Accordingly neuroimaging offers the opportunity to replicate results arrived at in pure behavioral experiments, such as the choice-of-institutions game discussed in the previous section. The evidence produced thus far suggests that both sets of investigations support one another, and, therefore, that individual and aggregate behaviors have mutual effects on each other.

\section{Evolutionary Economics/ACE Complexity Thinking}

I combine these two different research programs here because they reach very similar conclusions with respect to the issue of individual and aggregate behavior. Indeed, though the two programs have two separate sets of origins, they overlap on a number of counts that arguably reflect their shared diachronic orientations. Evolutionary economics is a research program concerned with the evolutionary analysis of long-run change that derives from evolutionary theory in biology and sociobiology, and efforts to extend and modify this form of analysis in connection with human social behavior and social-cultural evolutionary processes (Nelson 1995; Vromen 1995). $\stackrel{20}{ }$ ACE/complexity thinking has similar origins, but adds an emphasis on the mathematics of nonlinear dynamic systems and simulation models as compared to evolutionary economics' preference for theorizing based on empirical research. Both assume that evolutionary theorizing rejects accounts of economic change that employ "mechanical analogies" (Nelson $\underline{1995,53)}$.

Evolutionary economics approaches in particular develop arguments about systems that are subject to processes of random variation but also exhibit selection processes that winnow those variations. Evolutionary systems consequently show both strong inertial tendencies working to 
preserve what survives selection and also continuous change as the introduction of new variety through random mutation modifies those systems. Thus behavior of a system in the aggregate is continuously affected by the behavior of its changing elements, which in turn are affected by the selection behavior of the system.

ACE/complexity thinking similarly emphasizes dynamic interaction between a system's elements and its structure. The behavior a system's elements exhibit produces aggregate patterns or structures in the system. Because this structure is emergent, the behavior of the system's elements then adapts to it. The system's structures are then further changed, the elements further adapt, and so on in a continuous process of change through time. A class example is W. Brian Arthur's El Farol bar problem (Arthur 1994). One hundred people independently decide whether to show up at the El Farol bar. If many predict the bar will be crowded, the bar ends up being empty. But should the bar be empty, they revise their prediction, then expecting it to be empty, and all go, but it ends up being crowded, leading them to then predict the bar will be crowded, and so on. Predictions thus depend on predictions, and no correct expectations model is available. In contrast, in rational expectations models, agents somehow know in advance what model is correct (and everyone knows that everyone knows this is the correct model), so that aggregate behavior is fully known in advance, and agents need never revise their behavior.

\section{Synchronic and Diachronic Forms of Explanation}

All the research programs reviewed earlier, then, adopt elements of an embedded individual conception, but, as should now be clear, they do so in quite different ways according to the different types of objections they make to the standard conception. To make the nature of that conception and its critique clear, these objections were organized according to which of its three (linked) properties they target: preference exogeneity, indirect interaction, and absence of feedback effects from aggregate to individual behavior. But under each objection I have also provided discussions of approaches that reflect either more synchronic or more diachronic concerns in order to emphasize the deeper differences between these approaches. In the discussion in this section, I further pursue these differences to examine what types of contributions they make to a general conception of the individual as an embedded agent.

As noted at the outset, conceptions of the individual can be evaluated according to two criteria needed to explain the (personal) identity of the individual (Davis 2003b). The individuation criterion requires that a conception of the individual show how individuals are distinct and independent from one another. Individuation is largely a synchronic concern. The reidentification criterion requires that a conception of the individual show how individuals can be shown to be the same separate entities across a process in which some or even many of their characteristics change. Re-identification is largely a diachronic concern. Note also, however, that neither framework is particularly well suited to addressing the other framework's natural focus. Because synchronic forms of explanation largely bracket through-time or through-process considerations to focus on the character of an entity or mechanism, they do not really address whether individuals are re-identifiable through change. Because diachronic forms of explanation 
emphasize change and process, they tend to ignore the status and individual credentials of particular entities. This suggests that the conceptions (or elements of conceptions) of the individual we find in the new research programs - to the extent that they offer essentially synchronic or diachronic forms of explanation - are likely to be incomplete, and that a complete conception of the individual satisfying both criteria will need to combine elements of both synchronic and diachronic research programs. Because the research programs with the more synchronic orientation are more "micro" in nature, and the research programs with the more diachronic orientation are more "macro" in nature, this further suggests that an adequate embedded individual conception, as might emerge from some combination of the new research programs in economics, needs to combine both micro and macro aspects. $\frac{21}{}$

The research programs with synchronic forms of explanation, then, are classical game theory, behavioral economics, behavioral game theory, and neuroeconomics. Should these research programs move toward synthesis in the future or be increasingly accommodated to one another in Pickering's terms, then it seems reasonable to suppose that the rationality assumptions of classical game theory are most likely to be given up (or significantly modified), because they are contested in one way or another by all the remaining programs in this group. At the same time, that game theory has become central to behavioral, experimental, and neuroeconomics research suggests that it is likely to remain essential to synchronic forms of investigation. We might consequently label this synthesis experimental game theory, where this encompasses complimentary behavioral and neuroeconomics strategies.

The research programs with diachronic forms of explanation are EGT, evolutionary economics, and ACE/complexity economics. Here there are arguably greater barriers to mutual accommodation and synthesis by virtue of there being two quite different views of individual agents. On the one hand, EGT and evolutionary economics both subsume individual agents in evolutionary processes. With the more radical view of EGT, strategies are players, and individual agents "are simply passive vehicles for these strategies" (Ross 2005, 198), while in evolutionary economics individuals need not be human individuals and need not survive in any particular form through a given evolutionary process. On the other hand, ACE/complexity approaches, as ground-up, agent-based forms of investigation, presuppose individual agents (human and otherwise), and investigate how these particular agents adapt to dynamic processes. We might distinguish these two opposed kinds of views as evolutionary-process and evolutionary-agent strategies. Accommodation of these strategies to one another does not seem possible within the boundaries of the programs as they are currently pursued.

There accordingly seem to be two quite different possible future pathways available for the new research programs taken as a whole. If synchronic and diachronic forms of explanation are integrated, and micro and macro approaches are developed together in a shared framework, then the reconceptualization of individuals in an experimental game theory could be linked up with the evolutionary-agent approach in ACE/complexity accounts, because both frameworks emphasize individual agents. Alternatively, should evolutionary-process accounts prevail, synchronic and diachronic forms of explanation in the new research programs would likely not link up, thus tending to reproduce the current division between micro and macro in terms of two research programs largely opposed to one another on the place and significance of individuals in economic explanation. 
One motivation for the first scenario is a preference for a unity of science view. But philosophers' and scientists' preferences may be irrelevant when it comes to how economics actually develops. A second, perhaps stronger motivation is grounded in the availability of critique. That is, when micro and macro explanations are not reconciled, proponents of each may argue for the reduction of the other to their own framework. This is the basis of neoclassical microfoundations reasoning, where the critique advanced is that the macro must ultimately be

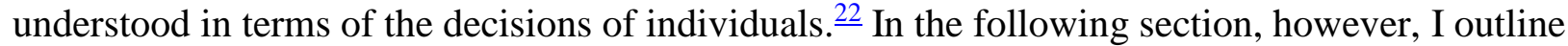
another microfoundations critique for a pathway the new research programs might take that favors the combination of experimental game theory and the evolutionary-agent approach. The difference between this argument and the standard microfoundations argument is that, whereas the latter as based on the atomist conception of the individual and is reductionist, the former argument, as based on an embedded individual conception, is not reductionist, and thereby has an appeal the standard view lacks.

\section{Embedded Individual Microfoundations}

The standard case for microfoundations involves a transcendental argument that supposes macroeconomic relationships must be explainable in terms of the behavior of individuals. As individuals exist, and as macroeconomic relationships are aggregative and do not make reference to individuals, they must somehow be "reduced to" or re-interpreted in terms of individual behavior. At root in the argument, however, is the idea that individual behavior and aggregate behavior cannot be combined in a single representation, thus requiring one or the other. Should this view be given up, and individual behavior and aggregate behavior be seen as somehow related, the traditional reductionist project ceases to have meaning. This alternative view naturally finds support in embedded individual conceptions, which, by definition, combine individual and aggregate behavior. Thus, embedded individual conceptions short-circuit reductionism. At the same time, if individual behavior and aggregate behavior are represented as related and mutually determining, explanations of aggregate behavior that exclude explanations of individual behavior, such as arguably is the case in the evolutionary-process approach, make the same mistake as traditional microfoundations arguments, and are at best incomplete. An embedded individual microfoundations would accordingly incorporate an evolutionary-agent approach.

But how would such a view provide microfoundations were the project not reductionist? Essentially an embedded individual microfoundations project constitutes a focus of analysis rather than an interpretive substrate. Individuals remain a central concern (for the reasons set forth at the outset), but their investigation (also transcendentally) presupposes and simultaneously requires examination of the aggregative relationships they occupy. This type of investigation clearly demands attention to a balance between individuals' embeddedness and independence that is not needed in atomistic individual microfoundations arguments, which assume individuals to be always independent. This type of investigation also demands attention to whether embedded individuals are sustainably independent, because if they are not, they could arguably be said to drop out of our explanations, as in evolutionary-process approaches. 
Here I do not attempt to set out such an explanation, since this task must presuppose the elaboration of particular substantive arguments about how the synchronic and diachronic research programs discussed earlier might be synthesized. But such an explanation, I suggest, can proceed in terms of two criteria, that is, by evaluating proposed individual conceptions according to whether they allow us to individuate and re-identify the economic agents they assume. Satisfying the re-identification criterion, it should be added, likely constitutes the more difficult task, since there is a clear debate in diachronic research programs regarding whether individuals are passive placeholders in evolutionary processes. Further, significant difficulties confront evolutionary-agent approaches regarding individual re-identification across change, because it is not clear how individuals' adaptations to changing social structures are compatible with their re-identification as self-same individuals. $\underline{23}$ Indeed, then, which of the two broad scenarios for the future of economics as it develops out of the new research programs transpires - a single unified program or reproduction of the division between micro and macro- depends on these issues.

\section{Concluding Speculations}

It was noted earlier that the new research programs in economics have hardly made the conception of the individual their chief concern. Thus, their development is likely to be driven by other factors, and their adoption of particular conceptions of the individual to be more a byproduct of other considerations. At the same time, most of the new research approaches in economics work implicitly with new conceptions of the individual, ones that I have argued all depart from the standard atomistic conception. This by itself may cause more attention to be paid to those conceptions, since it would seem ultimately to be bound to become clear to most practitioners that they are working with conceptions of the individual at odds with the conception that has been a pre-eminent marker of economics for over a century. Indeed, the standard view of the individual has long had more than scientific significance, since it is also one fixed in the popular understanding of economics, both on account of the way economics has long represented itself as a science of individual choice, and because economic micropolicy, which impacts the world, is formulated in terms of individuals. Moreover, already a vigorous debate over the implications of thinking about individuals as less than rational - because of (embedding) framing effects - has surfaced in regard to the discussion of paternalism vis-à-vis free market prescriptions (Camerer \& Loewenstein 2003).

It might also be argued that it is in the nature of a transition from one dominant approach (neoclassicism) to another - where this specifically involves the import of other science technologies - that a kind of interregnum period is likely to prevail when technical questions are

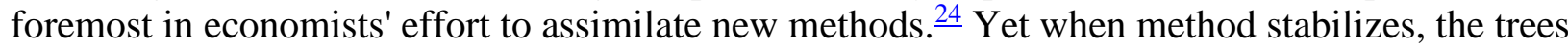
slide into the background to reveal the shape of the forest. Then arguably the perennial questions re-emerge for philosophers regarding individuals, markets, and value. 


\section{References}

Allais, M. (1953). "Le comportement de l'homme rationnel devant le risque: critique des postulats et axiomes de l'ecole americaine." Econometrica 21: 503-556.

Find This Resource

Amman, H., Kendrick, D. \& Rust, J., Eds. (1996). Handbook of Computational Economics, Vol. 1. North Holland: Elsevier.

Find This Resource

Arthur, W. B. (1994). "Inductive Reasoning and Bounded Rationality." American Economic Review 84 (2): 406-411.

Find This Resource

Aumann, R. (1989). “Game Theory.” In J. Eatwell, M. Milgate \& P. Newman, Eds., The New Palgrave: a Dictionary of Economics. London: Macmillan.

Find This Resource

Axelrod, R. (1984). The Evolution of Cooperation. New York: Basic Books. Find This Resource

Binmore, K. (1999). "Why Experiment in Economics?” Economic Journal 109: F16-24.

Find This Resource

Brooks, R. (2002). Robot: The Future of Flesh and Machines. London: Penguin.

Find This Resource

Camerer, C. \& Loewenstein, G. (2003). "Behavioral Economics: Past, Present, Future.” In C. Camerer, G. Loewenstein \& M. Rabin, Eds., Advances in Behavioral Economics. Princeton: Princeton University Press.

Find This Resource

Camerer, C. (2003) Behavioral Game Theory: Experiments in Strategic Interaction, Princeton: Princeton University Press.

Find This Resource

Camerer, C. and Fehr, E. (2004) "Measuring Social Norms and Preferences Using Experimental Games: A Guide for Social Scientists.” In J. Heinrich et al., Eds. Foundations of Human Sociality, 55-95. Oxford: Oxford University Press.

Find This Resource

Camerer, C. and Ho, T. (1999) "Experience-Weighted Attraction Learning in Normal Form Games." Econometrica 67 (4): 827-874.

Find This Resource 
Camerer, C., Loewenstein, G. \& Prelec, D. (2005). "Neuroeconomics: How Neuroscience Can Inform Economics.” Journal of Economic Literature 43: 9-64.

Find This Resource

Chomsky, N. (1955 [1975]). The Logical Structure of Linguistic Theory. Cambridge: MIT Humanities Press, Microfilm. Re-issue New York: Plenum Press, 1975.

Find This Resource

Chomsky, N. (1965). Aspects of the Theory of Syntax. Cambridge, MA: MIT Press.

Find This Resource

Colander, D. (2000). “The Death of Neoclassical Economics.” Journal of the History of Economic Thought 22 (2): 127-144.

Find This Resource

Cubitt, R., Starmer, C. \& Sugden, R. (2001). "Discovered Preferences and the Experimental Evidence of Violations of Expected Utility Theory." Journal of Economic Methodology 8 (3): 385-414.

Find This Resource

Davis, J. (2003a). "The Conception of the Individual in Non-Cooperative Game Theory." Tinbergen Institute Discussion Paper, 2003-095/2, http://www.tinbergen.nl/home.html.

Find This Resource

Davis, J. (2003b). The Theory of the Individual in Economics. London: Routledge.

Find This Resource

Davis, J. (2006a). “Complexity Theory's Network Conception of the Individual.” In A. Giacomin \& C. Marcuzzo, Eds., Money and Markets. Cheltenham,England: Elgar.

Find This Resource

Davis, J. (2006b). "The Turn in Economics: Neoclassical Dominance to Mainstream Pluralism?" Journal of Institutional Economics 2 (1): 1-20.

Find This Resource

Fehr, E. \& Gächter, S. (2000). "Fairness and Retaliation: The Economics of Reciprocity." Journal of Economic Perspectives 14: 159-181.

Find This Resource

Gürerk, Ö., Irlenbusch, I. \& Rockenbach, B. (2006). "The Competitive Advantage of Sanctioning Institutions." Science 312: 108-111.

Find This Resource

Harnad, S. (1987). "Category Induction and Representation,” in S. Harnad, ed., Categorical Perception: The Groundwork of Cognition. New York: Cambridge University Press. Find This Resource 
Harnad, S. (1990). “The Symbol Grounding Problem.” Physica D 42: 335-346.

Find This Resource

Harrison, G. (1994). "Expected Utility and the Experimentalists.” Empirical Economics 19: 223253.

Find This Resource

Harsanyi, J. (1967/1968). "Games with Incomplete Information Played by Bayesian Players." Management Science 14: 159-82, 320-34, 486-502.

Find This Resource

Harsanyi, J. (1995). “Games with Incomplete Information.” American Economic Review 85 (3): 291-303.

Find This Resource

Henrich, J., Boyd, R., Bowles, S., Gintis, H., Fehr, E., \& Camerer, C., Eds. (2004). Foundations of Human Sociality: Ethnography and Experiments in 15 small-scale Societies. Oxford: Oxford University Press.

Find This Resource

Kahneman, D. \& Tversky, A. (1979). "Prospect Theory: An Analysis of Decision under Risk." Econometrica 47 (2): 263-291.

Find This Resource

Kirman, A. \& Teschl, M. (2006). "Searching for Identity in the Capability Space." Journal of Economic Methodology 13: 299-325.

Find This Resource

Kirman, A. (1997). "The Economy as an Interactive System.” In W. B. Arthur, S. Durlauf \& D. Lane, Eds., The Economy as an Evolving Complex System II. Reading, MA: Addison-Wesley. Find This Resource

Lichtenstein, S. \& Slovic, P. (1971). "Reversals of Preference between Bids and Choices in Gambling Decisions.” Journal of Experimental Psychology 89: 46-55.

Find This Resource

Maynard Smith, J. \& Price, G. (1973). “The Logic of Animal Conflict.” Nature 146: 15-18. Find This Resource

Maynard-Smith, J. (1982). Evolution and the Theory of Games. Cambridge, England: Cambridge University Press.

Find This Resource

McCulloch, W. \& Pitts, W. (1943). "A Logical Calculus of Ideas Immanent in Nervous Activity.” Bulletin of Mathematical Biophysics 5: 115-133.

Find This Resource 
Mirowski, P. (2002). Machine Dreams: Economics Becomes a Cyborg Science. Cambridge, England: Cambridge University Press.

Find This Resource

Nelson, R. (1995). "Recent Evolutionary Theorizing About Economic Change." Journal of Economic Literature 38: 48-90.

Find This Resource

Payne, J., Bettman, J. \& Johnson, E. (1992). “Behavioral Decision Research: A Constructive Processing Perspective. ”Annual Review of Psychology 43: 87-131.

Find This Resource

Pickering, A. (1995). The Mangle of Practice. Chicago: University of Chicago Press.

Find This Resource

Plott, C. (1996). "Rational Individual Behavior in Markets and Social Choice Processes: The Discovered Preference Hypothesis." In K. Arrow, E. Colombatto, M. Perlaman \& C. Schmidt, Eds., The Rational Foundations of Economic Behavior, 225-250. London: Macmillan and New York: St Martin's Press.

Find This Resource

Rizvi, S. (1994). “Game Theory to the Rescue?” Contributions to Political Economy 13: 1-28. Find This Resource

Rizvi, S. (1997). "Responses to Arbitrariness in Contemporary Microeconomics." History of Political Economy 29: 273-288.

Find This Resource

Robbins, L. (1935 [1932]). An Essay on the Nature and Significance of Economic Science, $2^{\text {nd }}$ ed. London: Macmillan.

Find This Resource

Ross D. (2007). "Integrating the Dynamics of Multi-level Economic Agency." Philosophy of Economics Handbook. Oxford: Oxford University Press.

Find This Resource

Ross, D. (2005). Economic Theory and Cognitive Science: Microexplanation. Cambridge, MA: MIT Press.

Find This Resource

Samuelson, L. (2005). "Economic Theory and Experimental Economics." Journal of Economic Literature 43: 65-107.

Find This Resource

Searle, J. (1992). The Rediscovery of the Mind. Cambridge, MA: MIT Press.

Find This Resource 
Searle, J. 1980. "Minds, Brains, and Programs." Behavioral and Brain Sciences 3: 417-424. Find This Resource

Slovic, P. (1995) “The Construction of Preferences.” American Psychologist 50: 364-371.

Find This Resource

Smith, V. (1989). “Theory, Experiment and Economics.” Journal of Economic Perspectives 3: 151-169.

Find This Resource

Strogatz, S. (2001). "Exploring Complex Networks." Nature 410: 268-276.

Find This Resource

Sugden, R. (2001). "The Evolutionary Turn in Game Theory." Journal of Economic

Methodology 8: 113-130.

Find This Resource

Tesfatsion, L. \& Judd, K., eds., (2006). Handbook of Computational Economics, Vol. 2, AgentBased Computational Economics. North Holland: Elsevier.

Find This Resource

Tesfatsion, L. (2006). "Agent-Based Computational Economics: A Constructive Approach to Economic Theory." In L. Tesfatsion \& K. Judd, Eds., Handbook of Computational Economics Vol. 2: Agent-Based Computational Economics. Amsterdam: Elsevier.

Find This Resource

Testfatsion, L. (2001). "Structure, Behavior, and Market Power in an Evolutionary Labor Market with Adaptive Search." Journal of Economic Dynamics and Control 25: 419-457.

Find This Resource

Tversky, A. \& Kahneman, D. (1992). "Loss Aversion in Riskless Choice: A ReferenceDependent Model." Quarterly Journal of Economics 106 (4): 1039-1061.

Find This Resource

Vromen, J. (1995). Economic Evolution: On Inquiry into the Foundations of New Institutional Economics. London: Routledge.

Find This Resource

\section{Notes:}

(1.) Thanks without implication go to Fredrik Hansen, Floris Heukelom, Harro Maas, Abu Rizvi, and Leigh Tesfatsion, and the members of the workshop.

(2.) I argue in Davis (2003b) that this conception of the individual as a distinct being is circular in that the individual is picked out in terms of the idea of 'own' preferences. The conception allows that two individuals could have identical preferences, but would still be distinct 
individuals by virtue of those preferences belonging separately to each. The concept of belonging presupposes that which is to be picked out.

(3.) For more on Alan Turing, see Mirowski (2002).

(4.) Noam Chomsky (1955 [1975]; 1965) held that language capacity involves information processing that relies on a "deep" generative grammar that could be understood as syntactic symbol manipulation, an elementary form of which would employ Boolean algebra.

(5.) Warren McCulloch, a physiologist, and Walter Pitts, a logician, supposed that the human nervous system could be understood as universal computing device. In their seminal 1943 paper, "A Logical Calculus of the Ideas Immanent in Nervous Activity," they showed that configurations of neurons could perform any calculations computable by a Turing machine, and generated a mathematical model of the neuron, in which collections of neurons acted as "logic gates," now known as the McCulloch-Pitts neuron.

(6.) The Sonnenschein-Mantel-Debreu results were a significant stimulus for this development (cf. Rizvi 1997).

(7.) See Davis (2003b, Chapter 5) for a discussion of the emergence of functionalism in postwar neoclassical economics in the work of Kenneth Arrow, Paul Samuelson, and others.

(8.) Searle also created the distinction between strong AI and weak AI, in which the former identifies the computer and mind, and the latter involves computational simulation of some aspects of mind.

(9.) Leigh Tesfatsion recalls that at a 1996 UCLA workshop she, Robert Axtell, Charlotte Bruin, and Axel Leijonhufvud 'discussed naming the field 'agent based economics.' Consequently, this is why I called the website that I developed in late 1996 the 'agent-based economics website.' However, I soon discovered that many analytical microeconomists felt they were already doing 'agent-based economics' simply by means of having a utility maximizing consumer agent! So I changed the name of the website to the 'agent based computational economics' (ACE) website to try to indicate that we were referring to something quite distinct from current mainstream economics. This is the name I still use for the Web site [http://www.econ.iastate.edu/tesfatsi/ace.htm] today" (Testfatsion, personal communication, 5 May 2006).

(10.) Externalities constitute the exception.

(11.) "It is not enough that each player be fully aware of the rules of the game and the utility functions of the players. Each player must also be aware of this fact, i.e., of the awareness of all the players; moreover, each player must be aware that each player is aware that each player is aware, and so on ad infinitum. In brief, the awareness of the description of the game by all players must be a part of the description itself” (Aumann 1989, 473). 
(12.) Drawing on game theory applications to the Cold War, Harsanyi's example distinguishes American and Russian types whose causal factors pertain to their locations in the United States and the Soviet Union.

(13.) These are labeled semiconditional payoff functions.

(14.) I say "intention," because it may be argued that Harsanyi's assumption that individuals know their own types inadvertently re-introduces elements of the standard view (cf. Davis 2003a).

(15.) An analogous but slightly different argument can be applied to the classical sequentialmove or extensive form game (cf. Ross 2005, 201ff).

(16.) A parallel anthropological game theory investigation relies on non-experimental field data to examine strategic behavior across cultures (Henrich et al. 2004).

(17.) Thus, Vernon Smith's famous slogan is, "institutions matter" (Smith 1989).

(18.) Also, that migration occurred over repeated play, or that players did not select the higher payoff institution on the first round(s) of the game, was interpreted to indicate that individuals lack rational foresight.

(19.) See the paper by Don Ross in this volume for this point (Ross 2007).

(20.) According to most commentators, EGT falls outside the evolutionary economics research program on account of its classical game theory origins, though it shares roots in biological theory.

(21.) In contrast, the atomistic individual conception, which might be characterized as an exclusively synchronic form of explanation, involves only a micro type conception.

(22.) There are of course also macrofoundations arguments for micro.

(23.) Thus, one ACE/complexity account of individual identity argues that individuals do not/cannot retain self-same identities across processes of change (Kirman \& Teschl 2006).

(24.) Thus, some have defined the new approaches in economics in terms of tools rather than content as, for example, with David Colander's modeling characterization (Colander 2000), whereas dominant discourses appear to rather define themselves in terms of content (Robbins $1935[1932])$. 